\title{
Corrosion Inhibition Effect of a New Quinoline Derivative on Q235 Steel in $\mathrm{H}_{2} \mathrm{SO}_{4}$ Solution
}

\author{
Shujun Chen ${ }^{1, *}$, Siyi Chen ${ }^{1}$, Wenpo Li $^{2}$ \\ ${ }^{1}$ School of Chemistry and Chemical Engineering, Zunyi Normal University, Zunyi 563006, China. \\ ${ }^{2}$ School of Chemistry and Chemical Engineering, Chongqing University, Chongqing 400044, China. \\ *E-mail: shujunchen_znu@163.com
}

doi: $10.20964 / 2019.12 .36$

Received: 28 July 2019 / Accepted: 4 September 2019 / Published: 29 October 2019

In this work, a new quinoline derivative namely 5-benzyl-8-propoxyquinoline (5BPQ) has been studied to inhibit the Q235 steel corrosion in sulfuric acid. The protection ability of 5BPQ was investigated by electrochemical tests, weight loss and SEM measurements. Results indicate that the target 5BPQ has strong adsorption ability on the steel surface, thus shows excellent corrosion protective performance for steel in acid solution. The maximum inhibition efficiency of 5BPQ is 97.7\%), which is attributed to the effect of the heterocyclic rings. Scanning electron microscope (SEM) was utilized to further analysis the appearance of steel surface. Furthermore, the quantum calculation and molecular dynamics (MD) simulation further supported experiment. The systematic study gives a new guide to design novel quinoline derivative molecules to obtain the corrosion protection ability.

Keywords: Corrosion Inhibitor; Q235 steel; SEM; MD Simulation.

\section{FULL TEXT}

(C) 2019 The Authors. Published by ESG (www.electrochemsci.org). This article is an open access article distributed under the terms and conditions of the Creative Commons Attribution license (http://creativecommons.org/licenses/by/4.0/). 